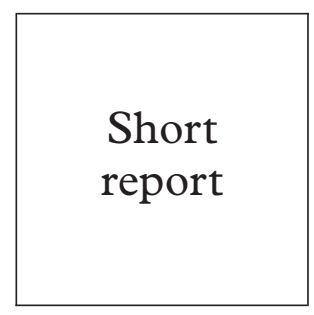

\title{
Short course oral prednisolone therapy in chronic abacterial prostatitis and prostatodynia: case reports of three responders and one non-responder
}

\author{
Sylvia Bates, Martin Talbot
}

Objective: To report on a small group of patients with chronic abacterial prostatitis/chronic pelvic pain syndrome treated with oral corticosteroids in order to suggest a hypothesis for a future randomised controlled trial.

Design: A retrospective, observational report.

Results: Three out of the four patients reported improvement in symptoms following steroid treatment.

Conclusions: These reports suggest that there is scope for conducting a randomised, placebo controlled study to investigate the role of oral corticosteroids in patients with chronic abacterial prostatitis/chronic pelvic pain syndrome who have failed on conventional therapy.

(Sex Transm Inf 2000;76:398-400)

Keywords: prostatitis; prostatodynia; steroids

\section{Introduction}

Chronic abacterial prostatitis (CAP) and prostatodynia are distressing and disabling conditions. The aetiology of the condition is poorly understood and unfortunately treatment options are both limited and frequently inadequate. Here we report on four cases where a short reducing course of oral corticosteroid therapy was used in the management of patients with persisting symptoms after conventional therapy.

\section{Case reports}

CASE 1

A 21 year old man presented with a 6 month history of penile shaft and perineal pain, worse on penile erection. He had previously been treated for three episodes of non-specific urethritis. Examination revealed a tender prostate gland and a wet mount preparation of the expressed prostatic secretions (EPS) showed clumping of polymorphonuclear leucocytes (PMNL). The EPS, mid-stream and postprostatic massage urines were sterile. A 3 month course of oral azithromycin $250 \mathrm{mg}$ daily was instituted with little effect. Subsequent treatment with a further 3 months of antibiotics together with non-steroidal anti-inflammatory drugs (NSAIDs) was also unsuccessful. By 6 months the patient had become depressed and impotent. However, the EPS showed signs of improvement. Supportive cognitive behavioural therapy and a small nocturnal dose of amitriptyline $25 \mathrm{mg}$ were unsuccessful. At 12 months, a short reducing course of oral prednisolone was commenced and resulted in significant improvement. (Our regimen is prednisolone, $5 \mathrm{mg}$ four times daily for 1 week, then three times daily for 1 week, twice daily for 1 week, then $9 \mathrm{mg}$ to $0 \mathrm{mg}$ over 1 week.) At 6 weeks the man reported feeling much better with pain of $1-2 / 10$ and successful penile tumescence with masturbation to ejaculation.
CASE 2

A 42 year old man had been treated for recurrent urinary tract infections, but with sterile urine. He complained of a dull, throbbing lower abdominal pain "like toothache," referred to both gonads. Clinical examination was normal. EPS was sterile but revealed $>12$ white blood cells per high power field (WBC/ hpf) on wet mount microscopy. The patient was initially treated with azithromycin $250 \mathrm{mg}$ daily for 3 months. The effect on the discomfort was variable and, because of continuing signs of inflammation on the EPS, the azithromycin (sometimes with ciprofloxacin $500 \mathrm{mg}$ twice daily as an alternative) was continued for a total of 12 months. Concomitant NSAIDs (ibuprofen $400 \mathrm{mg}$ three times daily or voltarol $50 \mathrm{mg}$ three times daily) were of variable symptomatic benefit. By 14 months, he was tired of coping with continuing pain and agreed to a reducing course of oral prednisolone. After 1 month the pain was less frequent and described as $1 / 10$ "on a bad day". He reattended 26 months later with a different complaint and reported that he had had no more "prostatitis trouble."

CASE 3

A 36 year old man was referred by the urology services with chronic prostatitis. The EPS and bacterial localisation studies were normal. Prostatodynia was diagnosed and intermittent, prolonged courses of antibiotic therapy with ciprofloxacin $500 \mathrm{mg}$ twice daily and trimethoprim $200 \mathrm{mg}$ twice daily were tried without success. NSAIDs did not relieve his symptoms. The patient derived some benefit from monthly support sessions, but by 14 months the pain was still $6 / 10$. Following a reducing course of oral prednisolone, he appeared much happier and by 16 months he described the pain as $0-1 / 10$ on a bad day, for him a tolerable level.
Accepted for publication 18 July 2000 
CASE 4

This 33 year old man with prostatodynia had suffered with lower abdominal pain, radiating to the groins, for 5 years. Clinical examination demonstrated a tender prostate gland, but the EPS and bacterial localisation studies were normal. Antibiotic therapy had had little effect on the pain. Ultrasound scan of the renal tracts, intravenous urography, and bladder histology were all within normal limits.

He was clinically depressed and had been started on amitriptyline $150 \mathrm{mg}$ daily. This medication had no effect on his pain. Genitofemoral nerve ablation with cryotherapy, lumbar sympathectomy, trazodone, carbamazepine, and oral NSAID therapy was similarly ineffective.

Prostatectomy had been discussed, but a second opinion had been sought before surgery. The patient agreed to a short course of corticosteroids, but by 4 weeks had reported no benefit. This therapy was therefore judged unsuccessful.

\section{Discussion}

Patients with CAP or prostatodynia may present with a variety of symptoms, including pains referable to the perineum, lower abdomen, penis and gonads, and pain or discomfort on ejaculation. ${ }^{1}$ Drach et al first proposed a classification of disease associated with prostatic symptoms in $1978 .^{2} \mathrm{CAP}$ was diagnosed if sterile prostatic fluid contained more than 10 $\mathrm{WBC} / \mathrm{hpf}$ on microscopy. Prostatodynia was diagnosed if symptomatic subjects had normal prostatic fluid on microscopy and culture. ${ }^{3}$ This classification makes a clear distinction between the two conditions. However, there is significant overlap and many believe these conditions to be a single entity. Meares has subsequently reported that there is no reason to distinguish CAP from prostatodynia. ${ }^{4}$

More recently the classifications of "Chronic abacterial prostatitis/Chronic pelvic pain syndrome (CAP/CPPS) - inflammatory" (previously CAP) and "-Non-inflammatory" (previously prostatodynia) have been approved by the National Institutes of Health. ${ }^{5}$

The aetiology of CAB/CPPS is uncertain. Studies searching for an infective cause have reported conflicting results. ${ }^{67}$ Other possible aetiologies include autoimmune disease and chemical inflammation secondary to reflux of urine into the prostate. ${ }^{8}$ More recently, interest has focused on cytokines, especially tumour necrosis factor (TNF) and interleukin 1 (IL-1), which have been found in higher concentrations in the seminal fluid of men with abacterial prostatitis than in controls. ${ }^{9}$ Cytokines regulate inflammatory and immune responses and this work supports the concept that inflammation is involved in the pathogenesis of prostatitis.

There is no consensus on the management of $\mathrm{CAB} / \mathrm{CPPS}$. Some authors consider a trial of antibiotics to be warranted in the absence of a specific treatment. ${ }^{10}$ Others believe they should be withheld until an infective cause is established. ${ }^{11}$ Non-steroidal anti-inflammatory analgesics, low dose tricyclic antidepressants, and centrally acting analgesics have all been used for symptom control. Psychological factors are important and patients benefit from a frank discussion about the nature of their condition. ${ }^{4}$

There have been no reports published in the literature regarding the use of oral corticosteroids in the treatment of CAP/CPPS. Meares suggested that a short reducing course of corticosteroids may help symptomatic flare ups, but no original reference was given for this approach. ${ }^{11}$ Lundgren et al found that the amount of inflammation in the prostate gland of rats injected with methylprednisolone was reduced at 4 weeks following administration compared with controls. Rat prostatitis is similar to the human condition and these findings support the hypothesis that corticosteroids should be further evaluated as a treatment option. ${ }^{12} \mathrm{We}$ were unsuccessful in finding any other references on a search of Medline, the Science Citation Index, Embase, or the Cochrane Library.

\section{Conclusion}

There is good evidence that inflammation is implicated in the pathogenesis of CAP/CPPS and steroid therapy has been shown to reduce inflammation in the rat prostate gland. However, the use of systemic steroids can be associated with a number of side effects including insomnia, hypertension, peptic ulceration, and a feeling of euphoria or depression. Therefore it is important to clearly establish the benefit of steroids in $\mathrm{CAB} / \mathrm{CPPS}$ before prescribing them for this condition. We have reported a very small number of cases without controls, but this report suggests that further investigation in a randomised, placebo controlled, double blind study with objective outcome measures should be undertaken.

Contributors: SB wrote the manuscript; MDT saw the patients and wrote the case reports.

1 Walker P, Wilson J. National guidelines for the management of prostatitis. Clinical Effectiveness Group (Association of Genitourinary Medicine and the Medical Society for the Study of Venereal Diseases). Sex Transm Inf 1999;75(Suppl 1):S46-50.

2 Drach GW, Fair WR, Meares EM, et al. Classification of benign diseases associated with prostatic pain: prostatitis or prostatodynia? F Urol 1978;120:266.

3 Meares EM, Stamey TA. Bacteriologic localisation patterns in bacterial prostatitis and urethritis. Invest Urol 1968;5: 492-518.

4 Meares EM. Prostatitis and related disorders. In: Walsh PC, Retik AB, Vaughan ED, Wein AJ, eds. Campbell's urology. 7 th ed. Vol 1. Philadelphia: WB Saunders, 1998.

5 Kreiger JN, Nyberg L, Nickel JC. NIH consensus definition and classification of prostatitis. $\mathscr{F} A M A$ 1999;282:236-7.

6 Brunner H, Weidner W, Schiefer H-G. Studies on the role of Brunner H, Weidner W, Schiefer H-G. Studies on the role of
ureaplasma urealyticum and mycoplasma hominis in prostatitis. F Infect Dis 1983;147:807-13.

7 Doble A, Thomas BJ, Furr PM, et al. A search for infectious agents in chronic abacterial prostatitis using ultrasound guided biopsy. Br f Urol 1989;64:297-301

8 Smart CJ, Jenkins JD, Lloyd RS. The painful prostate. $\mathrm{Br} \mathcal{F}$ Urol 1976;47:861-9.

9 Alexander RB, Ponniah S, Hasday J, et al. Elevated levels of pro-inflammatory cytokines in the semen of patients with chronic prostatitis/chronic pelvic pain syndrome. Urology 1998 52:744-9.

10 Thin RN, Simmons PD. Review of results of four regimens for treatment of chronic non-bacterial prostatitis. $\mathrm{Br} \mathcal{F} \mathrm{Urol}$ 1983;55:519-21.

11 Meares EM. Prostatitis: diagnosis and treatment. Drugs 1978;15:472-9.

12 Lundgren R, Holmquist B, Hesselvik M, et al. Treatment of prostatitis in the rat. The Prostate 1984:5:277-84. 